\title{
Research and Development of Controlled Auto-Ignition (CAI) Combustion in a 4-Stroke Multi-Cylinder Gasoline Engine
}

\author{
Jian Li, Hua Zhao, Nicos Ladommatos \\ Brunel University UK
}

Tom Ma

Ford Motor Company UK

\begin{abstract}
Controlled Auto-Ignition (CAI) combustion has been achieved in a production type 4-stroke multi-cylinder gasoline engine. The engine was based on a Ford 1.7L Zetec-SE $16 \mathrm{~V}$ engine with a compression ratio of 10.3 , using substantially standard components modified only in design dimensions to control the gas exchange process in order to significantly increase the trapped residuals. The engine was also equipped with Variable Cam Timing (VCT) on both the intake and exhaust camshafts. It was found that the largely increased trapped residuals alone were sufficient to achieve CAI in this engine and with VCT, a range of loads between 0.5 and 4 bar BMEP and engine speeds between 1000 and 3500 rpm were mapped for CAI fuel consumption and exhaust emissions. The measured CAl results were compared with those of Spark Ignition (SI) combustion in the same engine but with standard camshafts at the same speeds and loads. The comparison showed more than $30 \%$ reduction in BSFC and up to $99 \%$ reduction in NOx at low loads.
\end{abstract}

\section{INTRODUCTION}

Controlled Auto Ignition (CAI) combustion, also known as Homogeneous Charge Compression Ignition ( $\mathrm{HCCl}$ ), since it was first proposed in late 1970s [1,2], has been intensively studied in recent few years. It has been found that CAl combustion has low cyclic variations [3], better efficiency and fuel economy, and much less NOx emissions [4,5] comparing with SI combustion. While gasoline has been the fuel used in the majority of the published papers since the start of the studies of CAI combustion and would be the fuel in the future CAI combustion engine, other fuels such as methanol [6], natural gas $[7,8]$ and primary reference fuels [5] were also used in fundamental CAl combustion investigations. Recently diesel CAI combustion was studied $[9,10]$, to hopefully take advantage of the ultra-low NOx emissions of CAl combustion and reduce or even eliminate the problem of high particulate emissions associated with conventional diesel $\mathrm{Cl}$ engines.
CAl combustion is a new combustion process different from both gasoline $\mathrm{SI}$ and diesel $\mathrm{Cl}$ combustion. During CAl combustion premixed fuel and air mixture is compressed to a temperature so high (usually $1000 \mathrm{~K}$ or more) that auto ignition happens. Although of the similar auto ignition behaviour, CAl combustion is different from the knocking combustion that is characterised by violent heat releases and pressure rise rates. Its reaction rate is controlled and much slower thanks to the diluent (extra air and/or burnt gas) present in the mixture.

Once the auto ignition is initiated the reaction rate is not difficult to control, because the required amount of diluent (extra air and/or burnt gas) can be easily added in the charge during the mixture preparation process. However, with a fixed, low compression ratio and ambient inlet conditions, it is difficult to compress the charge to the very high auto ignition temperature in conventional SI engines, unless a large amount of hot residuals are trapped in the cylinders. In fact, to reach the high auto ignition temperature and initiate the CAI combustion is one of the major difficulties for the application of CAI combustion in a normal gasoline engine.

There are several methods to achieve the high auto ignition temperature. One of them is using hot residual gas in the cylinder. Mixing the hot residual gas with fresh charge can increase the charge temperature, so the charge can be compressed to a temperature high enough to initiate the auto ignition. Also the residual gas is a very effective diluent to reduce the reaction rate once the combustion is initiated. This method has been successfully used in 2-stroke engines [11,12] because it is not very difficult to trap a large amount of hot residual gas in the cylinder in 2-stroke engines due to their intrinsic scavenging characteristics.

There are two important factors when the hot residual gas is used to initiate CAI combustion [4]: (1) there must be a large amount of residual gas and;(2) the residuals must be hot enough (cold external EGR is not helpful for the auto ignition initiation). Otherwise the high auto ignition temperature will not be achieved under subsequent compression. However, in conventional 4-stroke engines the maximum amount of internal residuals is usually about 
$10-20 \%$ which is only a small fraction of the required amount to initiate CAI. It is extremely difficult to trap larger amount of hot internal residuals in a conventional 4-stroke engine with standard camshafts. Therefore, other methods have been employed to initiate CAI combustion in 4-stroke gasoline engines. One of the most popular ways is to heat the intake air. Thring [13] heated the intake air up to $400^{\circ}$ $\mathrm{C}$ at a compression ratio of 8 and obtained a CAl combustion range at different EGR rates and air fuel ratios. Increasing compression ratio is a useful method and Christensen et al [14] found that the preheated charge temperature required for $\mathrm{CAl}$ can be reduced when the compression ratio increases. They even obtained CAI combustion without heating the intake air (at $25^{\circ} \mathrm{C}$ ) at compression ratio 22.5. Aoyama et al [15] found supercharging is also helpful and managed to achieve CAI combustion in a engine with a compression ratio of 17.6 at $29^{\circ} \mathrm{C}$ intake temperature and about 1.28 bar intake pressure.

Unfortunately the above methods such as heating intake air and substantially increasing compression ratio are extremely difficult to be used in a practical engine. Exhaust gas through heat exchanger alone may not be able to heat the intake air up to the required temperature. And the electric heater not only increases the cost but also reduces the total efficiency as extra electric power is needed to drive the heater. Also heat inertia of the intake system may cause problems at transitions between CAI with intake heating and ambient inlet SI. High compression ratio is favourable to initiate CAl combustion but it may cause knock when the engine runs SI at high loads.

Therefore the way used in 2-stroke engines, of using internal residual gas, also seems to be the best way for 4stroke engines. To substantially increase the amount of trapped residuals, unorthodox camshaft configurations [4] and even electro-hydraulic valves [16] were employed and CAl combustion was successfully achieved in single cylinder 4-stroke engines without any other methods such as heating intake air and increasing compression ratio. In this paper camshaft configurations similar to those in Lavy et al [4] were used in a production type 4-stroke multi cylinder engine equipped with Variable Cam Timing (VCT) systems on both intake and exhaust camshafts. In this engine CAI combustion was achieved by only using special camshafts and VCT system, and a speed and load range for CAI combustion was obtained at lambda 1. The CAI fuel consumption and engine-out emissions were measured and compared with those of SI combustion. Also at some conditions the air fuel ratio was changed and the lean limit and the effects of lambda on CAI combustion were investigated.

\section{ENGINE SETUP}

Table 1 Engine specifications

\begin{tabular}{|l|l|}
\hline Stroke $(\mathrm{mm})$ & 83.5 \\
\hline Displacement $\left(\mathrm{cm}^{3}\right)$ & 1679 \\
\hline Compression ratio & 10.3 \\
\hline
\end{tabular}

The engine used in this work was a Ford 1.7L Zetec-SE $16 \mathrm{~V}$ four-cylinder, multi-point port injection production engine. Its specifications are listed in Table 1. The fuel used was a commercial unleaded gasoline of RON 95 complying with the British standard BS EN 228. Apart from the standard VCT system on intake side in this engine, another VCT system was cobbled onto the exhaust side to give the ability to adjust exhaust cam timing when the engine was running, which was proven to be very important to achieve CAl combustion. Another major modification to this engine is that special camshafts were used to restrict the gas exchange process in order to significantly increase the trapped residuals [17]. A Webcon Alpha-Plus ECU system, whose strategies are based on engine speed and throttle angle, was used to control the fuelling and ignition. Since all the tests were running at wide open throttle conditions, a dummy throttle was used and the signal from the dummy potentiometer was fed into the ECU to obtain the required fuelling. Also in this system there are facilities to finely adjust the fuelling and ignition timing manually. A sequential fuelling facility in this system is essential to provide the same fuelling events, hence same fuel preparation, for each of the four cylinders. An UEGO sensor was used to monitor the air fuel ratio and fine fuelling adjustment was made manually if necessary to maintain the required lambda.

An eddy-current dynamometer was employed to set the engine running at a desired speed, and a load cell was used to obtain the output torque. NOx and unburnt hydrocarbons were measured by using a SIGNAL heated vacuum NOx analyser and a SIGNAL FID total hydrocarbon analyser respectively. $\mathrm{CO}$ and $\mathrm{CO}_{2}$ were measured by an OLIVER K650 MOT analyser.

A pressure transducer was installed in one of the four cylinders to measure the in-cylinder pressure. The signal from this pressure transducer was fed into a PC based data acquisition system which ran a real-time analysis program. The program generated an array of pressure traces against crank angle, and from the pressure records it calculated the heat release data, indicated mean effective pressure (IMEP) and coefficient of variation of IMEP. Four thermocouples were installed in each of the four exhaust ports to monitor the exhaust temperatures and detect misfire should it happen.

A $10 \mathrm{~Hz}$ pulse generator, whose pulse width can be continuously varied, was built to control the duty cycle of the solenoid valves in the VCT system, therefore to change the cam timings.

\section{EXPERIMENTAL PRECEDURE}

\begin{tabular}{|l|l|}
\hline Bore $(\mathrm{mm})$ & 80 \\
\hline
\end{tabular}


Figure 1 Typical pressure traces of $\mathrm{SI}$ and $\mathrm{CAI}$

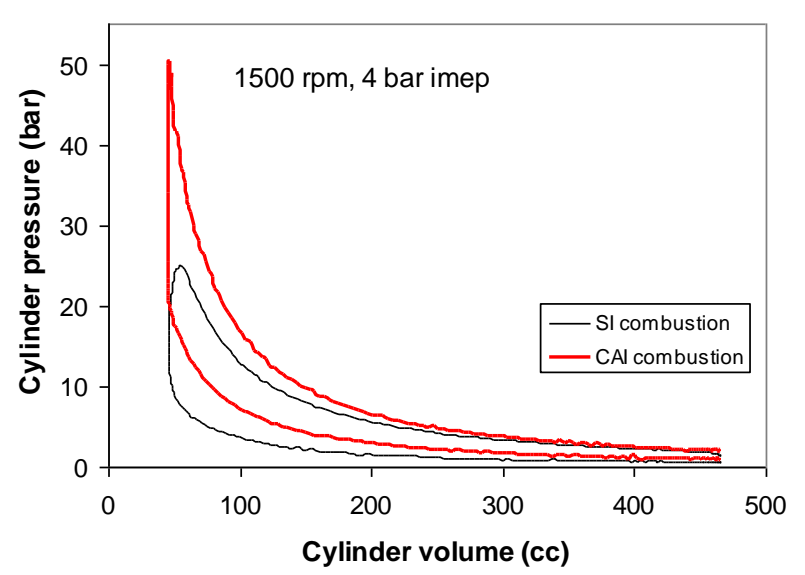

\section{combustion}

Cam timings, which would give as little residuals as possible, were chosen to start the engine by spark ignition. These timings resulted in a relatively small amount of residual gas in the cylinder and caused no problem to start the engine with SI combustion. After one or two minutes the engine was moderately warm and CAI combustion appeared, but it was unstable, i.e. CAI and SI combustion occurred intermittently for several cycles. Misfire was observed occasionally during this period. A few minutes later when the coolant temperature reached about $50-60^{\circ}$ C CAl combustion stabilised. However to minimise the effect of coolant temperature on CAI combustion all the tests were conducted when the coolant temperature was $90^{\circ} \mathrm{C}$ or over.

There were two ways to determine if CAI combustion was actually happening in the cylinders. One was to disconnect the ignition coil hence there was no spark in the cylinders. If the ignition coil was disconnected and the engine kept running it proved that the combustion in the cylinders was CAI. The other way was to check the in-cylinder pressure trace. Pressure records of CAI combustion, which usually displayed a distinctively sharp rise and much higher magnitude near TDC, were different from those of SI combustion (Figure 1). The latter way was usually used as the spark was kept on in the tests, and in the case that a CAI misfire happened the spark could ignite the mixture in the subsequent cycles. Also keeping the spark on in CAI mode did not cause any problems. Actually the spark had little effect on CAI combustion, changing the spark timing substantially showed virtually no effects on combustion.

During the tests the throttle was kept at wide open and the air flow was changed by varying the cam timings, which can be continuously changed by up to 40 degrees crank angle.

\section{RESULTS AND DISCUSSIONS}

There are several parameters that could be varied in the tests, for example cam timings, air fuel ratio, engine speed and load etc. Some of parameters were fixed while looking at the effects of other parameters. At first, the cam timings were fixed, which means that the air flow was kept unchanged because the throttle was always at wide open conditions and the cam timings were used to control the air flow, and the effects of air fuel ratio were investigated. By changing the air fuel ratio at a given air flow rate the BMEP was varied. In later tests the air fuel ratio was fixed at lambda 1 and the cam timings were varied to obtained different BMEP at each speed from 1000 to $3500 \mathrm{rpm}$.

TESTS WITH DIFFERENT AIR FUEL RATIOS - In these tests, the cam timings (IVO at $110 \mathrm{CA}$ after TDC and EVC at $80 \mathrm{CA}$ before TDC) were kept constant and the air fuel ratio was changed. At each speed, the air fuel ratio was set at slightly rich (about lambda 0.98), and then it was gradually increased until the mixture was too lean to sustain CAI combustion (the engine stalled). Figure 2 shows the air fuel ratio range and BMEP at different speeds for CAl combustion. Also showed in this figure are BSFC, exhaust temperatures and emissions in these tests.

At the lowest speed $1000 \mathrm{rpm}$, maximum lambda achieved is only about 1.14 . At $1500 \mathrm{rpm}$, it managed to reach about 1.27. As speed increases the maximum lambda decreases. One might think that lambda 1.27 is not very lean compared with the air fuel ratio achieved with CAI by other investigators $[5,13]$. However, there was a large amount of residuals in the cylinders, therefore the charge was still highly diluted. The rich side of lambda was not fully investigated because it would loss efficiency. Also, it was found in the experiment that CAl combustion is less tolerant with mixture enrichment than SI combustion. At 2000 rpm CAl misfire occurred at lambda 0.95. At 2500 rpm, the mixture could only be as rich as lambda 1 . Further enrichment resulted in unstable combustion and misfire. For speeds from 1000 to $1500 \mathrm{rpm}$, the rich limit was not fully investigated although CAl combustion at these speeds was more tolerant to enrichment than at high speeds. The BMEP was changed while varying air fuel ratio. Because the air flow did not change and the variation range for air fuel ratio is small, the BMEP did not change very much, only from about 1.3 bar to 3.5 bar.

As lambda increases the exhaust temperatures decrease owing to the reduction in fuelling. BSFC decreases a little as the mixture changes from slightly rich to slightly lean. And it then increases with lambda. It can be seen that at slightly lean conditions (about lambda 1.05) BSFC displays minimum values.

The trends of emission components, NOx, $\mathrm{HC}$ and $\mathrm{CO}$, varying with lambda are similar to those of SI combustion. NOx peaks at about lambda 1.05. As lambda changes from rich to stoichiometric and lean, CO decreases dramatically. It shows little change as lambda further increases and finally it slightly increases near the lean limit. HC emissions increase as the mixture becomes leaner indicating that the combustion becomes worse. 
Figure 3 Residual gas percentage at fixed cam timings

Figure 3 shows the residual gas percentage at different speeds for the fixed cam timings. At $1000 \mathrm{rpm}$ the residual is about $46 \%$, the lowest value in the speed range, but it is

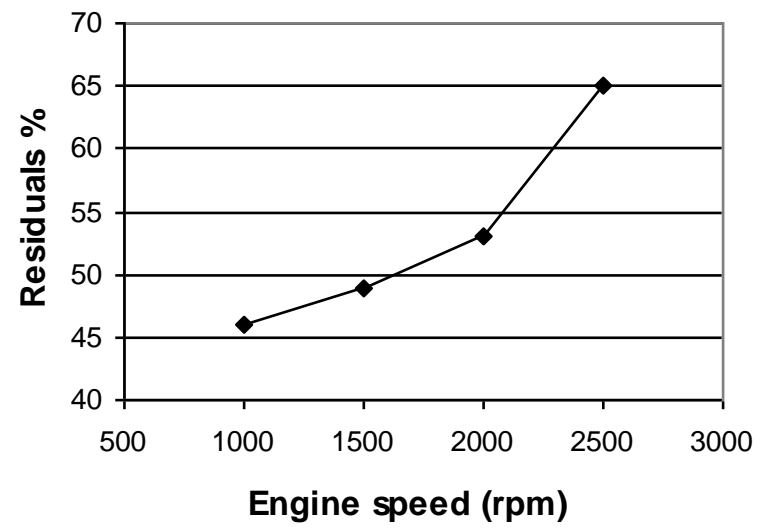

still enormously higher than the residual rate in SI engines which is about $20 \%$ at most. As the engine speed goes up, the residual rate increases due to less time for gas exchanges. At $2500 \mathrm{rpm}$ the residual rate reaches $65 \%$. The values in Figure 3 are only for these specific cam timings. At different cam timings, i.e. different air flow rate since the air flow rate is controlled by the cam timings, the residual rate is different even for the same speed. In fact, at $2500 \mathrm{rpm}$ the maximum residual rate observed for $\mathrm{CAl}$ combustion was as high as $75 \%$.

It can be seen from figures 2 and 3 that at lower speeds, 1000 and $1500 \mathrm{rpm}$, less residuals were trapped in the cylinders and hence higher BMEP was achieved. However, NOx emissions at these lower speeds are much higher at near stoichiometric conditions, indicating that the dilution rate was not large enough and higher residual percentage is needed to reduce NOx emissions. Therefore it is necessary to maintain higher residual rates while increasing the BMEP. Otherwise NOx emissions will largely increase and one of the major benefits of CAI combustion will be lost. The high load condition with the special camshafts could be achieved by supercharging, while using external EGR, or raising exhaust back pressure hence increasing trapped residuals, could maintain the high dilution rate required for low NOx productions.

It can be concluded that slightly lean mixtures at about lambda 1.05 give rise to minimum values of the fuel consumption BSFC and $\mathrm{CO}$ and $\mathrm{HC}$ emissions, and maximum NOx emissions. But even the maximum NOx emissions are only a small fraction of those of $\mathrm{SI}$ combustion. At lambda 1, the BSFC, CO and $\mathrm{HC}$ emissions are close to the minimum figures, and NOx emissions are slightly lower than peak values. Also if the engine runs at stoichiometric conditions, all the facilities existing in the current $\mathrm{SI}$ engines such as lambda control and three way catalysts can be directly utilised in the CAI engines without modifications. So tests at lambda 1 were conducted to investigate the speed and load range of CAI combustion and emissions.
RESULTS OF CAI COMBUSTION AT LAMBDA 1 - At lambda 1 engine tests were conducted at different engine speeds and loads. For a given speed the load was varied by changing the cam timings. Figure 4 shows the speed and load range within which CAl combustion was achieved in the engine. The lowest speed tested was $1000 \mathrm{rpm}$. Any speed lower than that was considered not typical for a real engine (unless at idle) hence not investigated. The maximum speed in figure 4 is $3500 \mathrm{rpm}$. In fact at a speed higher than $3500 \mathrm{rpm}$ CAl was achieved, but only in a tiny load range, therefore it is not included. At each speed there is a maximum and a minimum load. The upper limit is a result of restrictions of gas exchange. At those conditions the air flow rate is the maximum the engine can intake with the special cam timings. Knock did not happen normally even at the upper limit. Only at $1000 \mathrm{rpm}$ suspected knock was observed rarely at the maximum load. The lower load end is limited by misfire. At these conditions there were too much residual gas and its temperature is very low (figure 5). The mixture could neither be auto ignited (temperature too low), nor spark ignited (too much residuals). As speed increases the maximum load reduces due to the fact that at higher speed, there is less time for gas exchange process hence more residuals trapped in the cylinders and less fresh charge is inducted.

Figure 5 shows the exhaust temperature across the CAI speed and load range. The CAl exhaust temperature varies with speed and load similarly as the SI exhaust temperature does. An interesting thing in figure 5 is that no matter what the engine speed is, the exhaust temperature at the low load end is about 300 to $350^{\circ} \mathrm{C}$. This suggests that it is the exhaust gas temperature limits the low load and if the exhaust gas is cooler there is not enough energy in the exhaust gas to heat up the mixture to the required auto ignition temperatures.

Figure 6 shows the brake specific fuel consumption across the CAI range. BSFC mainly depends on load and does not change very much with engine speed. For the same speed BSFC reduces as the load increases. But for the same load at different speeds BSFC shows little change, especially at low load conditions.

Figures 7 - 9 give the NOx, $\mathrm{CO}$ and $\mathrm{HC}$ emissions of $\mathrm{CAl}$ combustion in the speed and load range. For a given speed, as load increases NOx increases, $\mathrm{CO}$ and $\mathrm{HC}$ decrease as expected. The variations of each of the three emission components with speeds are different. NOx does not change very much with speed at low and high speeds, but increases with speed in the mid-speed range. Speed hardly shows effects on $\mathrm{CO}$, especially at high speeds. HC decreases as speed increases suggesting that combustion at high speeds is better and more complete. The reasons why the three emission components behave like this in the speed and load range are not very clear and detailed combustion features of CAI need to be investigated. It is thought that analysis about the residual gas fraction and combustion details would be helpful to better understand the behaviour of BSFC and emissions. The analysis will be conducted in the near future in another paper. 
COMPARISION BETWEEN CAI AND SI RESULTS - TO study how the performance of a CAl combustion engine is relative to that of an $\mathrm{SI}$ engine, the measured CAI results were compared with those of SI combustion in the same engine with standard camshafts at the same speeds and loads

Figure 10 shows the percentage change of CAI BSFC relative to SI BSFC. In the whole CAI speed and load range, there is a BSFC improvement for CAl. At higher loads, the fuel economy improvement is small, only about $5-10 \%$ at 2.5 bar BMEP. As the load decreases the improvement becomes significant and it reaches about $30 \%$ at 1 bar BMEP. Further fuel consumption reduction is achieved at lower loads. The better fuel consumption comes from two sources. The first is that the engine is unthrottled with CAI combustion so there is a reduction in pumping work. This effect is much more important at low loads because at these conditions SI engines are usually highly throttled, the reduction in pumping work is enormous for unthrottled CAI combustion. At higher loads the throttling of $\mathrm{SI}$ engines is reduced and less improvement in BSFC is observed. The other reason for BSFC improvement is that during CAl combustion the sharp pressure rise occurs near TDC and it makes CAI combustion look like constant-volume combustion, which is the most efficient process. In figure 1 the typical P-V diagram of the power cycles of CAI and SI combustion is shown and the constant-volume like feature can be clearly seen on the CAI curve.

Figure 11 shows the percentage improvement in NOx emissions. In the CAl range $90-99 \%$ reduction in NOx emissions are observed. That means NOx emissions from $\mathrm{CAI}$ are only one hundredth to one tenth of those from SI combustion. This immense reduction is similar to the results of an effective catalyst. It may be argued that after treatment may not be necessary in this range for CAI combustion. The huge reduction in NOx emissions is a result of much reduced combustion temperatures. Due to the large amount of residual gas (especially at low loads) in the cylinders the typical temperatures of CAI combustion are around $1800 \mathrm{~K}$ while typical SI combustion temperatures are around $3000 \mathrm{~K}$. In the much cooler CAI combustion there is hardly any NOx formed. This is true at low load conditions during which_the readings from NOx analyser were close to figures of ambient air. At higher loads more energy is released during combustion and the temperature of the total mixture is higher, hence NOx is higher. But even at the upper end of the load the NOx from CAl is only about $10 \%$ of NOx from SI.

It can be seen from figure 12 that CAl combustion reduces CO emissions by 10 to $40 \%$ depending on speed and load. At low speed and high load conditions $\mathrm{CO}$ reduction is higher. However, $\mathrm{HC}$ emissions from CAl combustion are worse than in SI combustion. In figure 13 , a $50 \%$ to $160 \%$ increase in $\mathrm{HC}$ is found for CAl combustion. That means $\mathrm{HC}$ emissions from CAI are 1.5 to 2.6 times of those from $\mathrm{SI}$ combustion. The reason for the $\mathrm{HC}$ increase is not absolutely clear. It might be due to the low CAI combustion temperatures. At lower loads the combustion temperatures are even lower and more $\mathrm{HC}$ increases were recorded.
However the actual cause of the $\mathrm{HC}$ emission increase needs to be further investigated.

\section{CONCLUSIONS}

CAl combustion has been achieved in a production type 4stroke multi-cylinder gasoline engine without any special methods such as intake air heating and raising compression ratios. CAl combustion was achieved by utilising a large amount of trapped hot residual gas in the cylinders to heat the mixture. Relevant modifications to the engine (special cams and dual VCT) were made to obtain the required amount of residuals. The following conclusions can be drawn from the experimental results.

1. Using hot residuals gas is an effective and feasible way to initiate CAI combustion. The largely increased hot residuals alone, whose rate at one set of fixed cam timings was 46 to $65 \%$ in this engine, are sufficient to achieve CAl combustion.

2. In this engine the maximum air fuel ratio achieved for CAl combustion is about lambda 1.27. For different speeds the lean limit varies slightly. At slightly lean conditions (lambda 1.05) BSFC, $\mathrm{CO}$ and $\mathrm{HC}$ emissions have minimum values while NOx emissions peak. Rich mixtures are not favourable to CAl combustion at high speeds.

3. At lambda 1, a range of speed from 1000 to $3500 \mathrm{rpm}$ and load from 0.5 to 4 bar BMEP was obtained for CAI combustion. In this range, the fuel consumption and exhaust emissions of CAl combustion were measured and mapped. The upper limit of the load is a result of restrictions of gas exchanges. Supercharge plus external EGR or raising exhaust back pressure could extend this limit. The lower end of the load is limited by misfire (residual temperatures too low). To extend the lower limit is more difficult and some other ways may be needed to raise the in-cylinder temperatures.

4. CAl combustion shows a 5 to more than $30 \%$ reduction in fuel consumption and 90 to $99 \%$ reduction in NOx emissions. $\mathrm{CO}$ emissions from $\mathrm{CAl}$ are slightly lower than those from SI combustion. But unburnt hydrocarbons from CAl combustion are 1.5 to 2.6 times of those from SI combustion.

\section{ACKNOWLEDGEMENTS}

This work is a part of the 4-SPACE project, and the authors would like to thank the European Commissions for its financial support to the 4-SPACE Consortium, and other partners in this Consortium for their collaboration.

\section{REFERENCES}

1. Onishi, S., Hong, S., Shoda, K., Do Jo, P., and Kato, S., Active Thermo Atmosphere Combustion (ATAC) a new combustion process for internal combustion engines, SAE paper 790501, 1979.

2. Noguchi, M., Tanaka, Y., Tanaka, T. and Takeuchi, Y., A study on gasoline engine combustion by observation 
of intermediate reactive products during combustion, SAE paper 790840, 1979.

3. lida, N., Ichikura, T., Kase, L. and Yoshiteru, E., Selfignition and combustion stability in a methanol fuelled low heat rejection ceramic ATAC engine - analysis of cyclic variation at high wall temperatures and lean burn operation, JSAE review 18, pp233-240, 1997

4. Lavy, W., Dabadie, J., Angelberger, C., Duret, P.(IFP), Willand,J., Juretzka, A., Schaflein,J.(DaimlerChrysler), Ma, T. (Ford), Lendresse, Y., Satre, A. (PSA Peugeot Citroen), Schulz, C., Kramer, H. (PCl Heidelberg University), Zhao, H., Damiano, L. (Brunel University), Innovative ultra-low NOx controlled autoignition combustion process for gasoline engines: the 4-SPACE project, SAE paper 2000-01-1837, 2000

5. Oakley, A., Zhao, H., Ladommatos, N. and Ma, T., Experimental studies on controlled auto-ignition (CAI) combustion in a 4-stroke gasoline engine, International conference on $21^{\text {st }}$ century emissions technology, C588/019/2000, IMechE, 2001

6. lida, N., Combustion analysis of methanol-fuelled active thermo-atmosphere combustion (ATAC) engine using a spectroscopic observation, SAE paper 940684, 1994

7. Christensen M., Johansson, B. and Einewall, P., Homogeneous charge compression ignition $(\mathrm{HCCl})$ using isooctane, ethanol and natural gas - a comparison with spark ignition operation, SAE paper 972874, 1997

8. Chen, Z., Konno, M., Oguma, M. and Yanai, T. Experimental study of $\mathrm{Cl}$ natural gas/DME homogeneous charge engine, SAE paper 2000-010329, 2000

9. Ryan, T. and Callahan, T. Homogeneous charge compression ignition of diesel fuel, SAE paper 961160 , 1996

10. Kimura, S., Aoki, O., Kitahara, Y. and Aigoshizawa, E. Ultra-clean combustion technology combining a lowtemperature and premixed combustion concept for meeting future emission standards, SAE paper 200101-0200, 2001

11. Ishibashi, $Y$ and Masahiko, A., Improving the exhaust emissions of 2-stroke engines by applying the activated radical combustion, SAE paper 960742 , 1996

12. Duret, P. and Venturi, S., Automotive calibration of the IAPAC fluid dynamically controlled 2-stroke combustion process, SAE paper 960363

13. Thring, R., Homogeneous charge compression ignition ( $\mathrm{HCCl}$ ) engines, SAE paper 892068, 1989

14. Christensen, M. and Hultqvist, A., Demonstrating the multi fuel capability of a homogeneous charge compression ignition engine with variable compression ratio, SAE paper 1999-01-3679, 1999

15. Aoyama, T., Hattori, Y., Mizuta, J. and Sato, Y., An experimental study on premixed charge compression ignition gasoline engine, SAE paper 960081, 1996

16. Law, D., Allen, J. Kemp, D. and Williams, P., 4-stroke active combustion (controlled auto-ignition) investigation using a single cylinder engine with Lotus active valve train (AVT), International conference on $21^{\text {st }}$ century emissions technology, C588/006/2000, IMechE, 2000

17. Duret, P. and Lavy, J., Process for controlling selfignition in a 4-stroke engine, US patent 6082342 

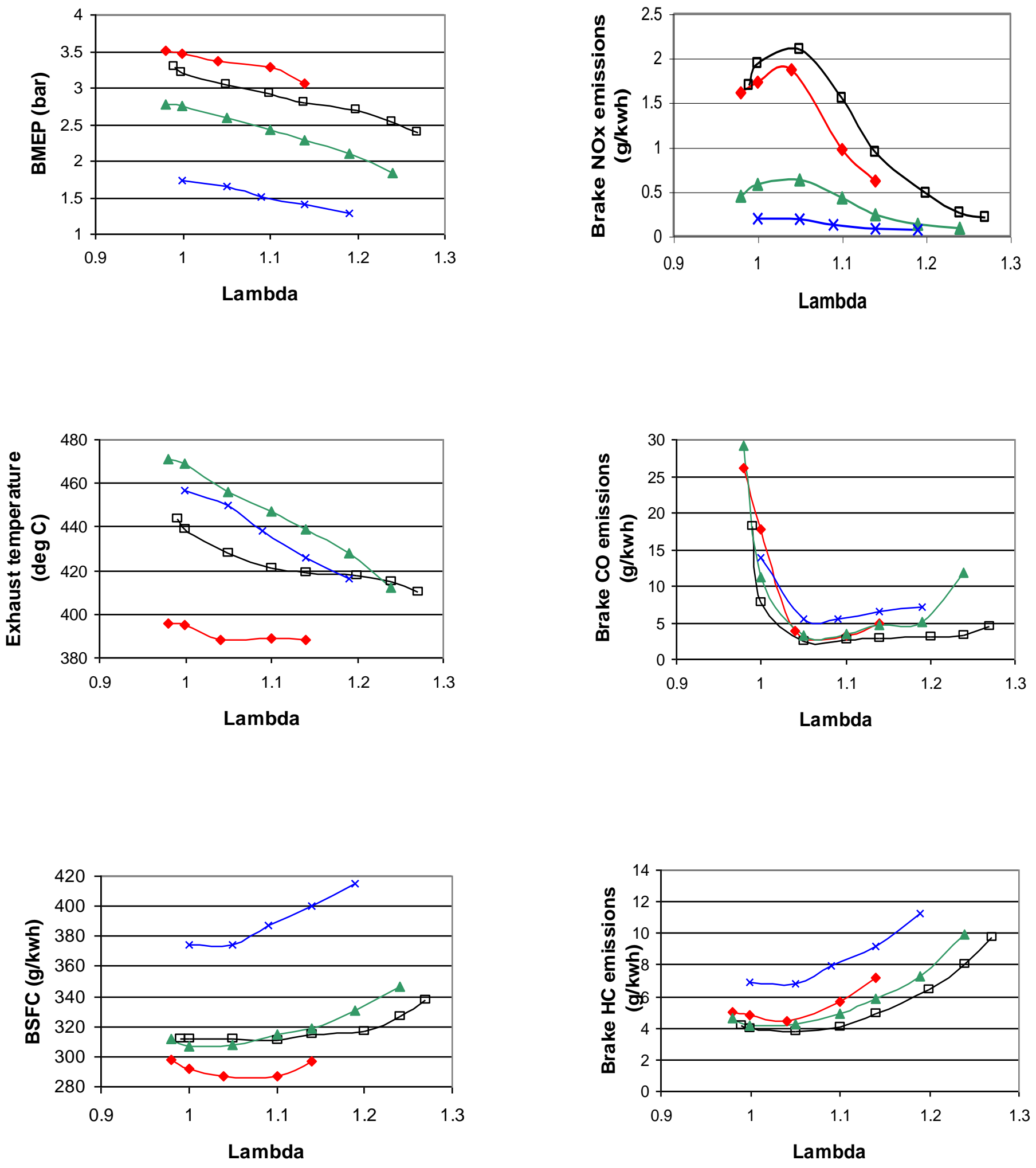

$\neg 1000 \mathrm{rpm} \longrightarrow-1500 \mathrm{rpm} \longrightarrow-2000 \mathrm{rpm} \longrightarrow 2500 \mathrm{rpm}$

$\sim 1000 \mathrm{rpm} \longrightarrow-\square-1500 \mathrm{rpm} \longrightarrow 2000 \mathrm{rpm} \rightarrow-2500 \mathrm{rpm}$ 


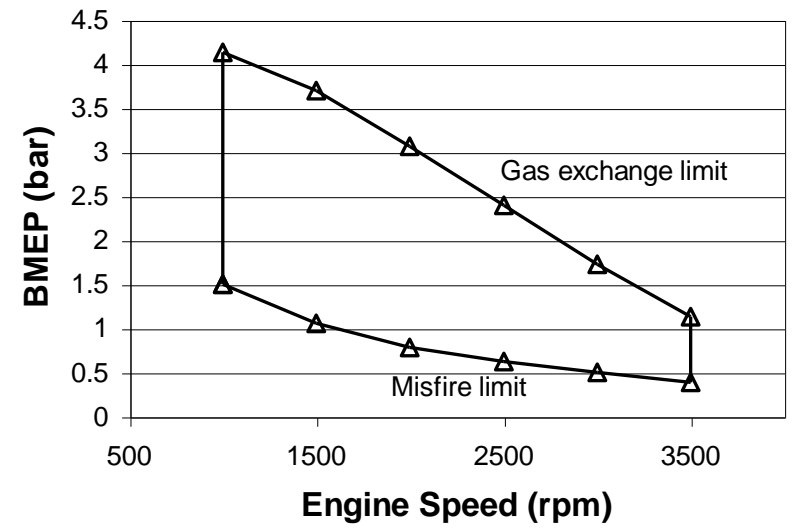

Figure 4 Speed and load range of CAI

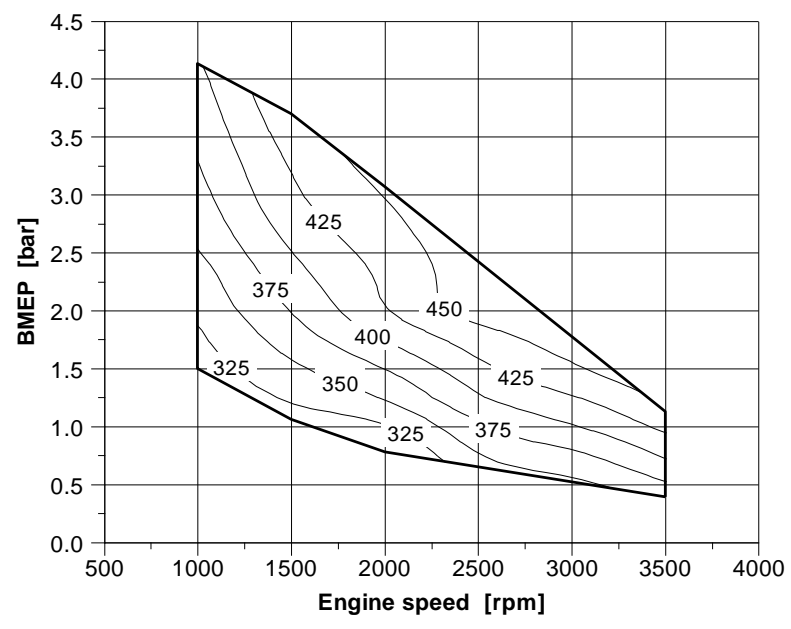

Exhaust temperature (deg C)

Figure 5 Exhaust temperature of CAI

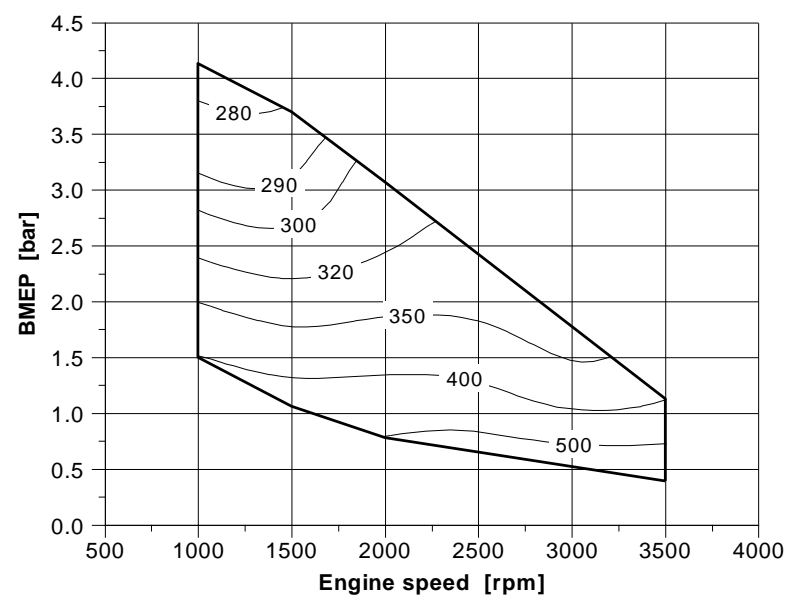

$\operatorname{BSFC}(\mathrm{g} / \mathrm{kwh})$

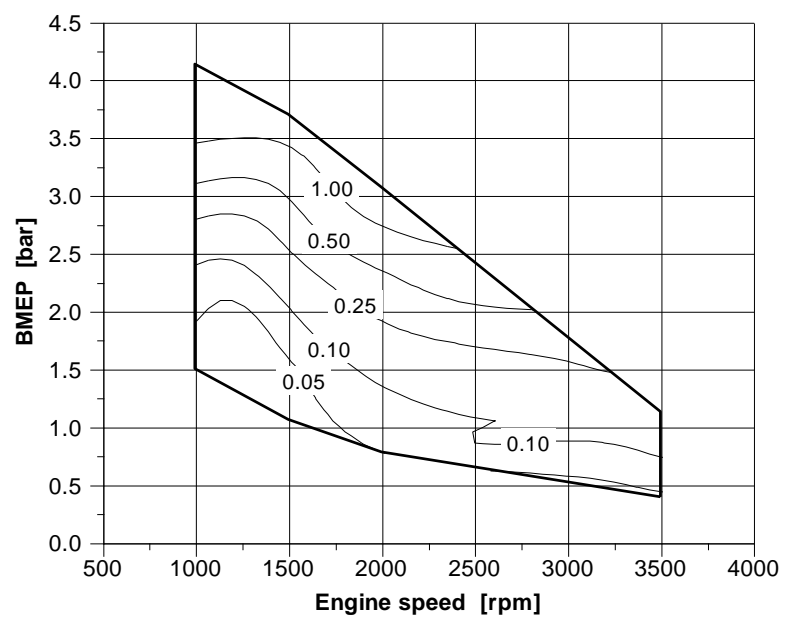

Brake NOx emissions (g/kwh)

Figure 7 Brake NOx emissions of CAI

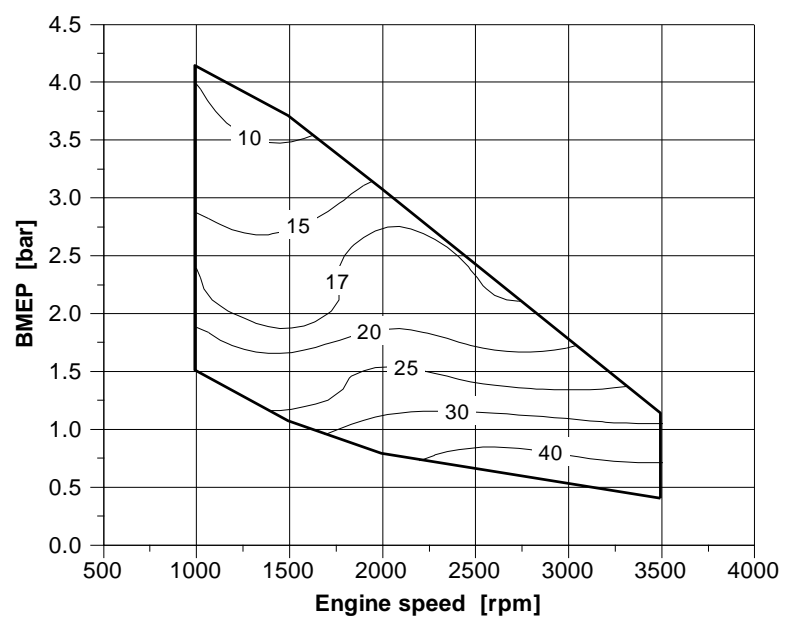

Brake CO emissions (g/kwh)

Figure 8 Brake $\mathrm{CO}$ emissions of CAI

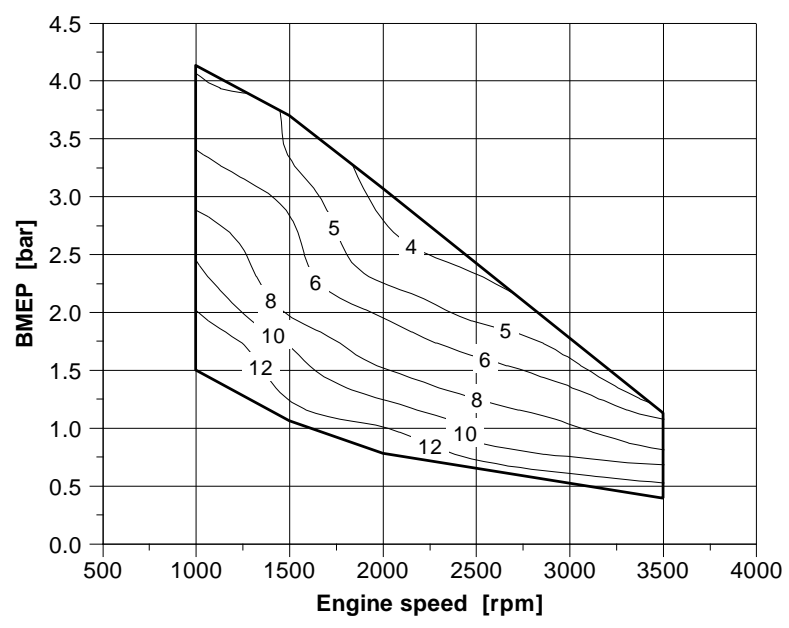

Brake HC emissions (g/kwh)

Figure 9 Brake HC emissions of CAl 


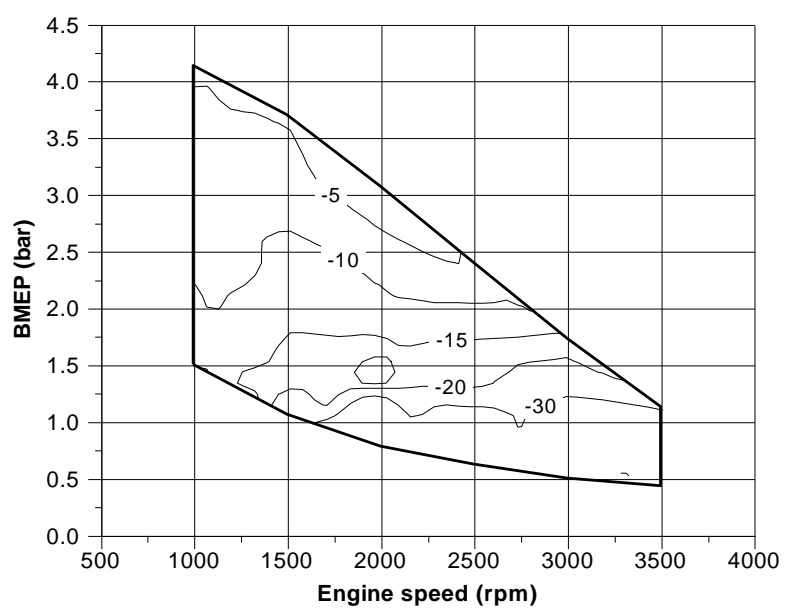

Percentage change of BSFC

Figure 10 Percentage change of BSFC

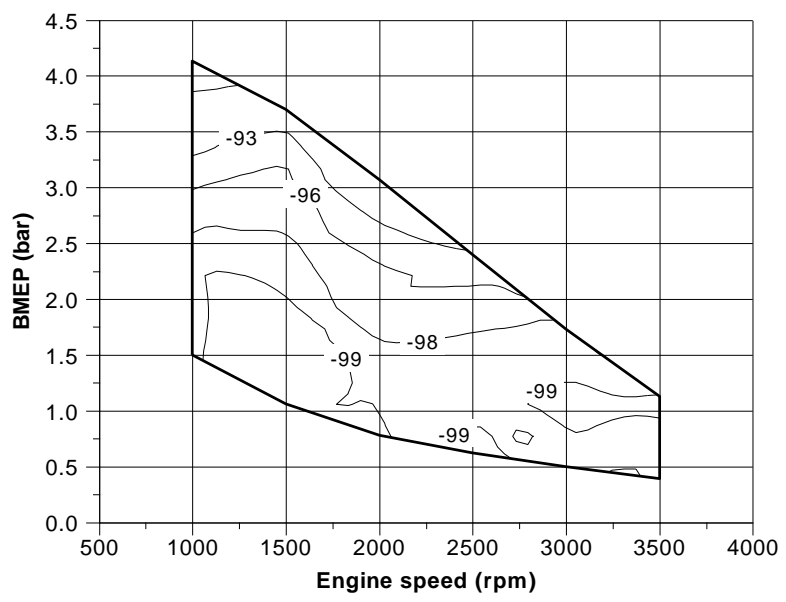

Percentage change of brake NOx emissions

Figure 11 Percentage change of brake NOx emissions

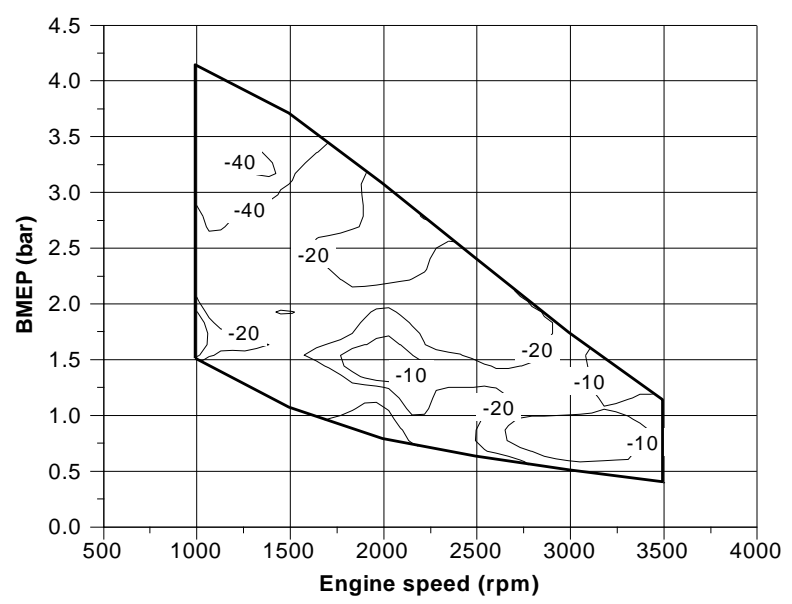

Percentage change of brake $\mathrm{CO}$ emissions

Figure 12 Percentage change of brake $\mathrm{CO}$ emissions

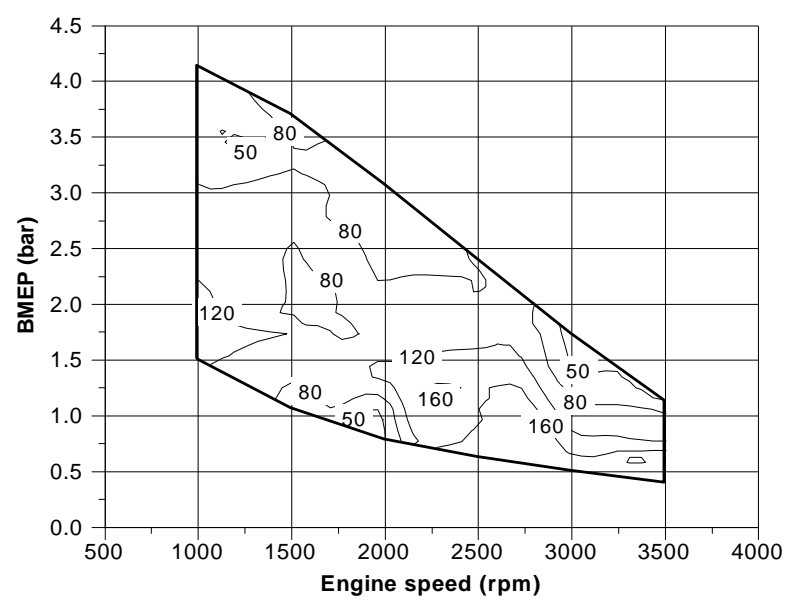

Percentage change of brake $\mathrm{HC}$ emissions

Figure 13 Percentage change of brake HC emissions 